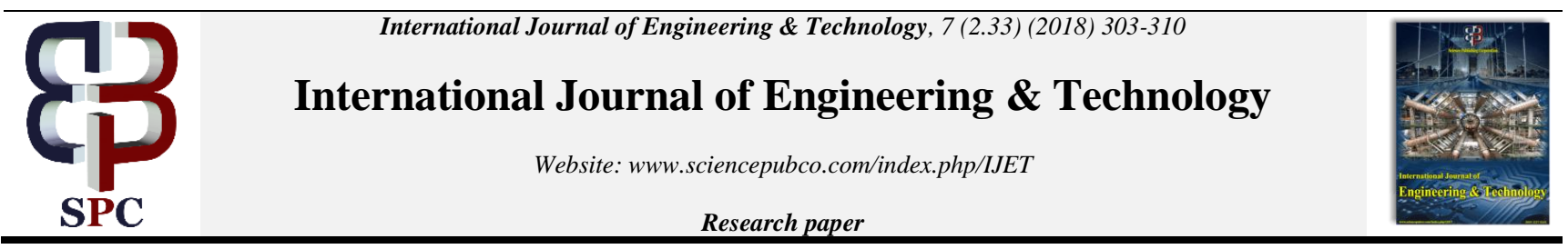

\title{
Analysis on Al6061-NI-graphite composite using squeeze casting method
}

\author{
S. Arunkumar ${ }^{1 *}$, M. Chandrasekaran ${ }^{2}$, T. Vinod Kumar ${ }^{1}$ \\ ${ }^{1}$ Assistant Professor Department of Mechanical Engineering, Vels Institute of Science, Technology and Advanced Studies (VISTAS), \\ Chennai -600117 \\ ${ }^{2}$ Professor and Director Department of Mechanical Engineering, Vels Institute of Science, Technology and Advanced Studies (VISTAS), \\ Chennai -600117 \\ *Corresponding author E-mail: gct.arunkumar@gmail.com
}

\begin{abstract}
In recent years, aluminum based composites have gained popularity in all the popularity in all emerging fields of technology owing to their superior stiffness and strength. This is because of the less wetting nature between the fortification and the framework and the difficulty of higher level of support expansion in to the grid. Notwithstanding, metal covered fortifications have possessed the capacity to beat these confinements to an exceptionally degree. NCG particles strengthened Al6061 network with different weight rates were manufactured by crush throwing strategy. The main advantages of composite materials are their high strength and stiffness, combined with low density, when compared with bulk materials, sanctioning for a weight reduction in the culminated part.

Aluminium based composite materials are leading ones in this area; they are fabricated using many methods, including squeeze casting pro-cesses. Squeeze casting makes materials properties relatively easy to control by mixing materials with different properties in various propor-tion. Samples of [5] and 10-wtpercentage reinforcement additament were synthesized and characterized. Heat transfer coefficients during squeeze cast of commercial aluminium were determined, by using the solidification temperature versus time curves obtain for varying applied pressure during squeeze casting process.
\end{abstract}

Keywords: Al6061; Squeeze Casting; Ni; Graphite; Microstructure Analysis.

\section{Introduction}

A composite material can be defined as a cumulation of two or more materials that results in better properties than those of the individual components used alone. In contrast to metallic alloys, each material retains its separate chemical, physical, and mechanical properties. The two constituents are reinforcement and a matrix. The main advantages of composite materials are their high vigor and stiffness, amalgamated with low density, when compared with bulk materials, sanctioning for a weight reduction in the culminated part.

The reinforcing phase provides the vigor and stiffness. In most cases, the reinforcement is harder, more vigorous, and stiffer than the matrix. The reinforcement is conventionally a fiber or a particulate. Particulate composites have dimensions that are approximately equal in all directions. They may be spherical, platelets, or any other customary or aberrant geometry. Particulate composites incline to be much more impuissant and less stiff than perpetual fiber composites, but they are conventionally much less extravagant. Particulate reinforced composites customarily contain less reinforcement (up to 40 to 50 volume percent) due to processing difficulties and brittleness.

The perpetual phase is the matrix, which is a polymer, metal, or ceramic. Polymers have low vigor and stiffness, metals have intermediate vigor and stiffness but high ductility, and ceramics have high vigor and stiffness but are brittle. The matrix (perpetual phase) performs several critical functions, including maintaining the fibers in the congruous orientation and spacing and bulwarking them from abrasion and the environment. In polymer and metal matrix composites that form a vigorous bond between the fiber and the matrix, the matrix transmits loads toughness rather than the vigor and stiffness, ergo, a low interfacial vigor bond is desirable.

\section{Experimental procedure}

The Al 6061 and nickel coated graphite is the main components used in the study.

Table 1: Chemical Composition of Al6061 Alloy

\begin{tabular}{llllllllll}
\hline $\begin{array}{l}\text { Compo- } \\
\text { nents }\end{array}$ & $\mathrm{Al}$ & $\mathrm{mg}$ & $\mathrm{Si}$ & $\mathrm{Fe}$ & $\mathrm{Cu}$ & $\mathrm{Zn}$ & $\mathrm{Ti}$ & $\mathrm{Mn}$ & $\mathrm{Cr}$ \\
\hline \multirow{4}{*}{ Amount\% } & $\mathrm{Res}$ & 0.8 & 0. & $\mathrm{Ma}$ & 0.15 & $\mathrm{Ma}$ & $\mathrm{Ma}$ & $\mathrm{Ma}$ & 0.04 \\
& $\mathrm{t}$ & - & 6 & $\mathrm{x}$ & - & $\mathrm{x}$ & $\mathrm{x}$ & $\mathrm{x}$ & - \\
& 1.2 & & 0.7 & 0.40 & 0.2 & 0.1 & 0.1 & 0.35 \\
\hline
\end{tabular}

\subsection{Aluminium 6061 Alloy}

The entire document should be in Times New Roman. The font sizes to be used are specified in Table 1.

Aluminium alloys are alloys in which aluminium (Al) is the predominant metal. There are two principle classifications namely casting alloys and wrought alloys. Cast aluminium alloys yield cost-effective products due to the low melting point, although they generally have lower tensile strengths than wrought alloys. The most important cast aluminium alloy system is $\mathrm{Al}-\mathrm{Si}$, where the 
high levels of silicon (4.0-13\%) contribute to give good casting characteristics. Aluminium alloys are widely used in engineering structures and components where light weight or corrosion resistance is required.

\subsubsection{Applications}

Aluminium 6061 is commonly used for the construction of aircraft structures such as wings and fuselages. It is used as it is more easily worked and remains resistant to corrosion even when the surface is abraded which is not in case of any other alloy. Used in automotive parts such as wheel spacers and manufacture of aluminium can use in packing of foodstuffs and beverages.

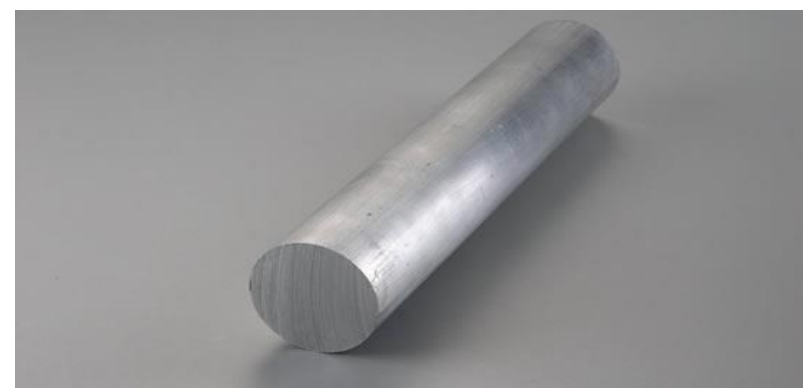

Fig. 1: Al 6061 Specimen.

Table 2: Properties of Unreinforced Aluminium T6 Alloys

\begin{tabular}{lllll}
\hline Alloys & $\begin{array}{l}\text { Yield } \\
\text { strength } \\
\text { Mpa }\end{array}$ & $\begin{array}{l}\text { Ultimate } \\
\text { strength Mpa }\end{array}$ & Elongation & $\begin{array}{l}\text { Young's } \\
\text { modulus Gpa }\end{array}$ \\
\hline 6061 & 275 & 310 & 20 & 69 \\
(T6) & & 524 & 13 & 73 \\
$2014(\mathrm{~T} 6)$ & 476 & 470 & 12 & 72 \\
$2124(\mathrm{~T} 6)$ & 325 & 470 & 9 & 74 \\
$2618(\mathrm{~T} 6)$ & 370 & 570 & 10 & 72 \\
$7075(\mathrm{~T} 6)$ & 505 & 485 & 7 & 80 \\
$8090(\mathrm{~T} 6)$ & 415 & 280 & 6 & 76 \\
A356(T6) & 205 & 320 & 3.5 & 72 \\
A380(T6) & 160 & & & \\
\hline
\end{tabular}

\subsection{Nickel coated graphite}

Nickel Coated Graphite is a graphite powder that has been completely encapsulated with a layer of nickel by the thermal decomposition process. It is used as lightweight filler for conductive gaskets (extruded, molded, sheet and Form-In-Place) and sealants. Other applications include plasma spray, friction products and graphitic aluminum.

Graphite is a very attractive candidate for aluminum-metal matrix composites. However, aluminum does not wet graphite, which makes the production of aluminum-graphite composites difficult. Nickel is a material known to be wetted by aluminum. In the presence of a nickel intermediate layer between the aluminum and graphite, wetting of the graphite by aluminum was expected to improve. To determine the wettability of aluminum on nickel coated graphite, the sessile drop technique along with a high temperature X-ray setup was used. Aluminum drops on substrates of graphite, electrolytic nickel, and nickel coated graphite were studied. Contact angles determined for these samples showed that graphite is non-wetting while the nickel coated graphite provided better wetting than electrolytic nickel. The aluminum/substrate interface of the samples was examined microscopically using scanning electron microscopy. Graphite exhibits smaller particle size and higher aspect ratio (length/thickness) than NCG particles. The electrical results showed that the percolation threshold of graphite and NCG filled PP composites occurred in the range of 10 to $20 \mathrm{vol} . \%$ and 15 to $25 \mathrm{vol} . \%$, respectively.

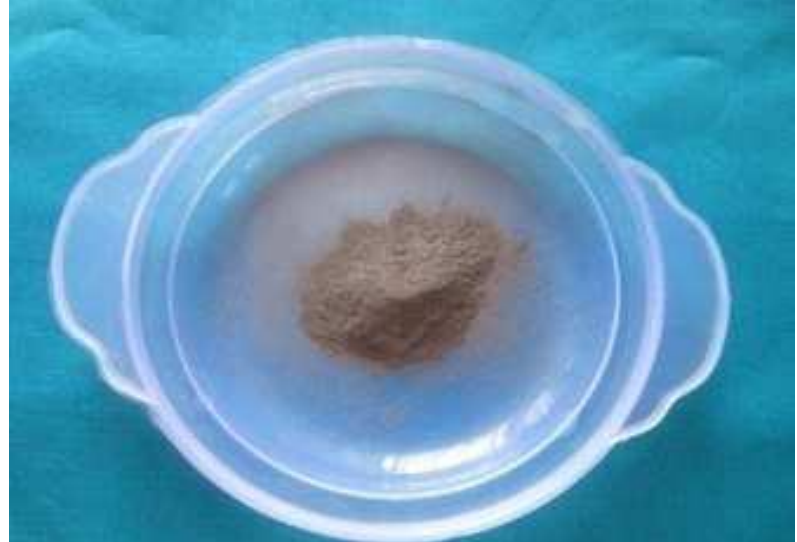

Fig. 2: Nickel Coated Graphite Powder.

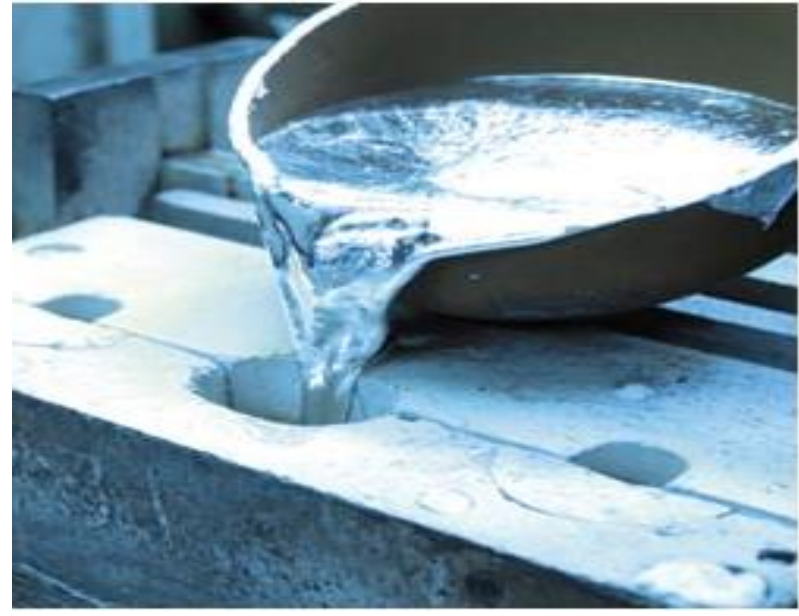

Fig. 3: Casting Processes

\subsection{Casting}

Casting is a manufacturing process by which a liquid material is usually poured into a mould, which contains a hollow cavity of the desired shape, and then allowed to solidify. The solidified part is also known as a casting, which is ejected or broken out of the mold to complete the process. Casting materials are usually metals or various cold setting materials that cure after mixing two or more components together; examples are epoxy, concrete, plaster and clay. Casting is most often used for making complex shapes that would be otherwise difficult or uneconomical to make by other methods. Metal casting is one of the most common casting processes. Metal patterns are more expensive but are more dimensionally stable and durable. Metallic patterns are used where repetitive production of castings is required in large quantities.

\subsubsection{Squeeze casting}

Squeeze casting, also known as liquid metal forging, is a combination of casting and forging process.

The molten metal is poured into the bottom half of the pre-heated die. As the metal starts solidifying, the upper half closes the die and applies pressure during the solidification process. The amount of pressure thus applied is significantly less than used in forging, and parts of great detail can be produced. Coring can be used with this process to form holes and recesses. The porosity is low and the mechanical properties are improved. Both ferrous and nonferrous materials can be produced using this method. The squeeze casting process uses an accurately measured or metered quantity of molten metal which is poured into a heated mould via a launder. The mould is closed to produce an internal cavity in the shape of the required component.The molten metal is forced/displaced into the available space of the die cavity. As with most casting processes, using a permanent pattern, the mould is coated with a suit- 
able release agent and for squeeze casting it is usually in the form of a graphite coating.

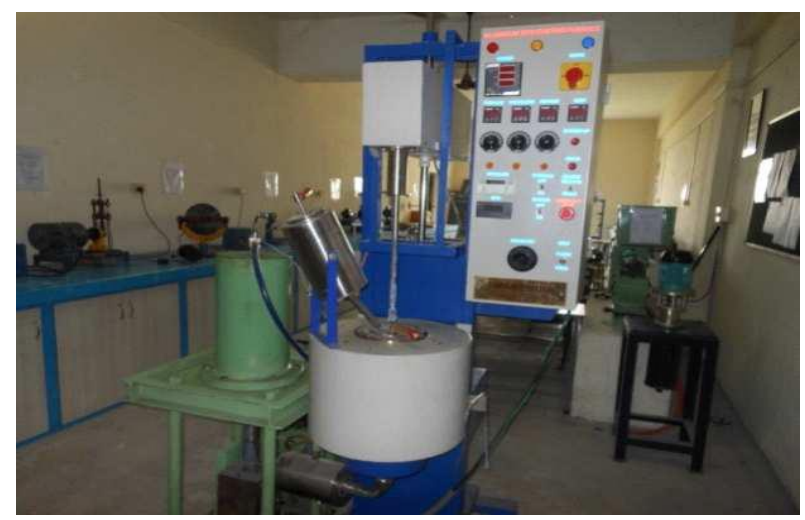

Fig. 4: Casting Processes.

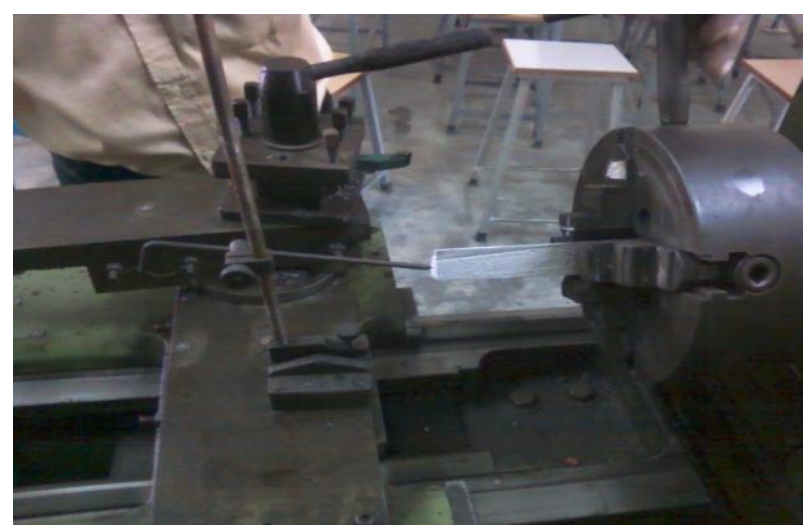

Fig. 5: Squeeze Casting Machine Setup.

The melts which have been cut using the hacksaw are turned to obtain a cylindrical rod. After turning operations are done the specimens are prepared for the various testing's to be carried. The prepared materials from both the melts are cut into the required dimensions. The edges of the melts are finished to produce a smooth finish for obtaining better results.

\section{Experimental process}

\subsection{Development of composites}

Initially, the furnace was turned on to heat to a temperature above $850^{\circ} \mathrm{C}$ and a holding time up to $1 \mathrm{hr}$. Aluminum alloy blocks were dropped in to the furnace sanctioning it to melt in the furnace. Meanwhile the powders which are to be integrated as reinforcement were preheated at $600-800^{\circ} \mathrm{C}$. The reinforcement is gradually incorporated in to the aluminum matrix melt through a dispenser while maintaining a constant stirring of $400 \mathrm{rpm}$ for 6 7 secs with a motorized stirrer. The opportune distribution of the reinforcement in to the matrix the drain plug is opened so that the melt permeates the pathway which is preheated to a temp of $650^{\circ} \mathrm{C}$. The ram of the squeezer is now pushed forward so that the entire melt is Subjected to a pressure of 50 tones with a setting time of 8-10secs. This constricting enhances the distribution of reinforcement uniformly in to the matrix there by minimizing the formation of pores in the cast samples.

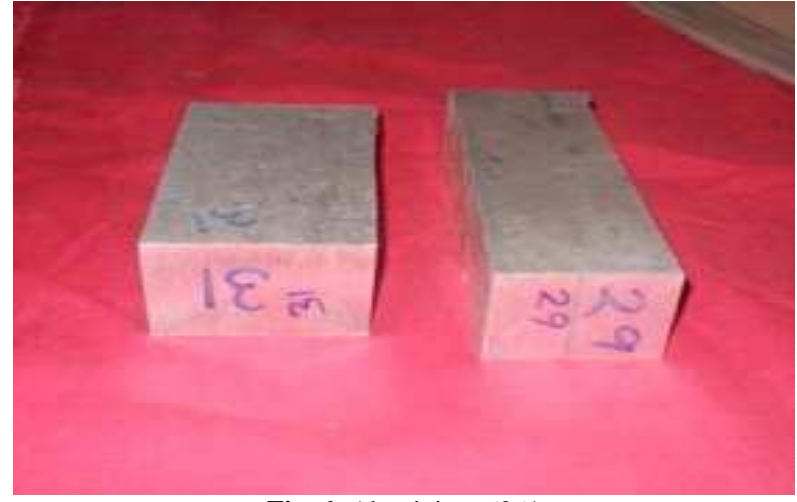

Fig. 6: Aluminium 6061

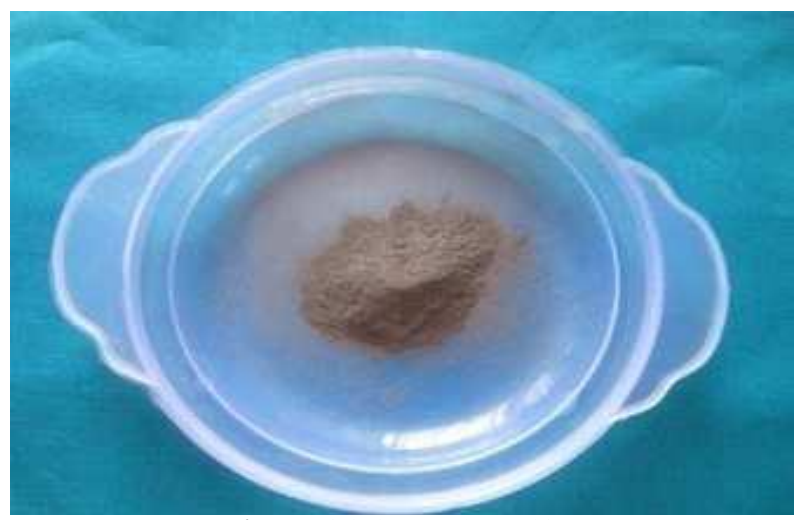

Fig. 7: Nickel Coated Graphite.

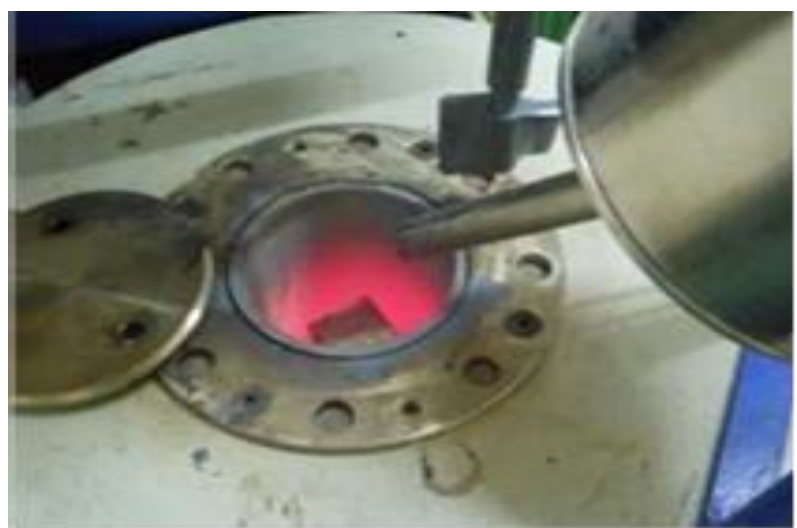

Fig. 8: Al 6061 and NCG Liquid Formation in the Furnace.

Table 3: Properties of Unreinforced Aluminium T6 Alloys

\begin{tabular}{llll}
\hline $\begin{array}{l}\text { Sample } \\
\text { No. }\end{array}$ & $\begin{array}{l}\text { Melt Tempera- } \\
\text { ture }\end{array}$ & $\begin{array}{l}\text { Die tempera- } \\
\text { ture }\end{array}$ & $\begin{array}{l}\text { Squeeze Pressure } \\
\text { Mpa }\end{array}$ \\
\hline 1. & 800 & 400 & 0 \\
2. & 800 & 400 & 30 \\
3. & 800 & 400 & 50 \\
4. & 800 & 400 & 70 \\
5. & 800 & 400 & 100 \\
6. & 800 & 400 & 130 \\
\hline
\end{tabular}

The samples were fabricated as two sets: the first being the samples under reinforcement of NCG with $5 \mathrm{wt} \%$ additament into the matrix melt and the second being the cumulation additament of $\mathrm{Ni}$ powder and Graphite powder in the proportion of $10 \mathrm{wt} \%$ in to the melt matrix. The cast samples were indexed so as to identify it for varying proportion of reinforcement coalescence.

The reinforcement powder is Nickel coated Graphite (N.C.G). The particle size is -300 mesh. The particles were integrated as reinforcement with weight $\%$ of 5and 10 within AA matrix. Graphite powder utilized in this work is of 400 mesh size. It is integrated discretely in to the matrix melt after preheating. Nickel powder of 1 micron size, $99.9 \%$ purity was utilized. 


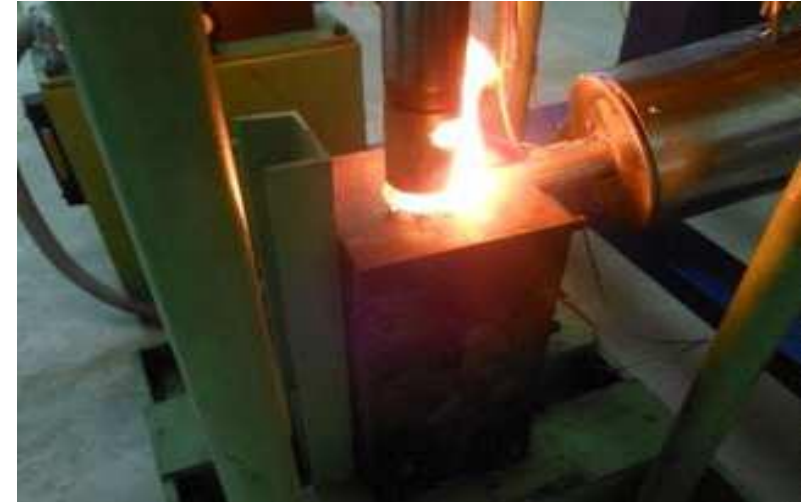

Fig. 9: Squeeze Displaced to Casting.

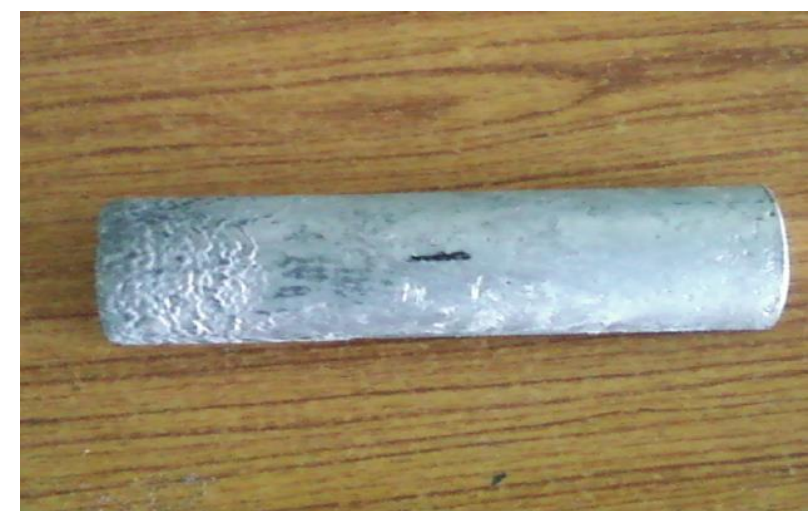

Fig. 10: The Melts Were Cut Into Two Halves Machined Being Ready for Various Testing.

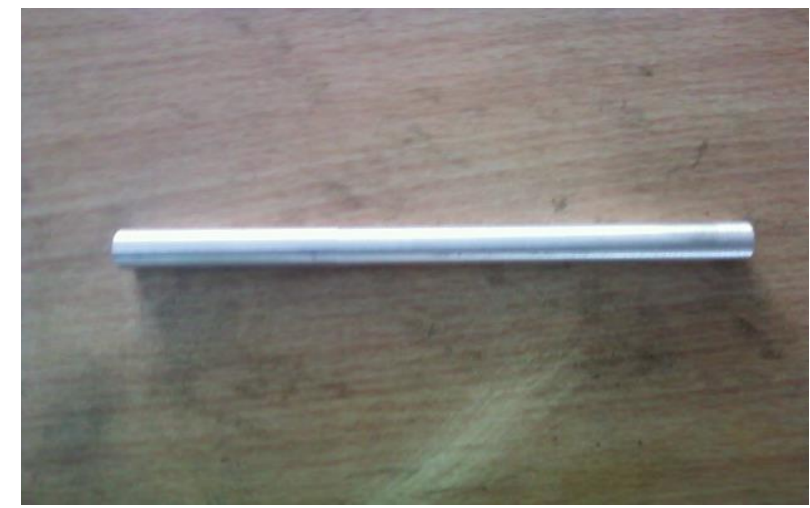

Fig. 11: Specimen Obtained by the Lathe Machining Process in Turning Operation.

\section{Results and discussions}

\subsection{Microstructure analysis}

Microstructure testing is done to examine the cracks and shrinkage of the materials. The edge surfaces of the cut out melt is placed under the optical microscope and the shrinkage cavities are found out for the various melt specimens. The microstructure testing is done on both the melts.

Both the melts are machined in the lathe machine by performing turning operation. The specimens of diameter $2.5 \mathrm{~mm}$ and length $5 \mathrm{~mm}$ are cut from the melts and placed for optical microscope testing. Microstructure shows interdendritic network of silicon particles, blades of $\mathrm{Fe} 2 \mathrm{Si} 2 \mathrm{Al} 9$ and mg2Si particles. $\mathrm{CuAl} 2$ distributed in a matrix of Aluminum solid solution throughout the structure.

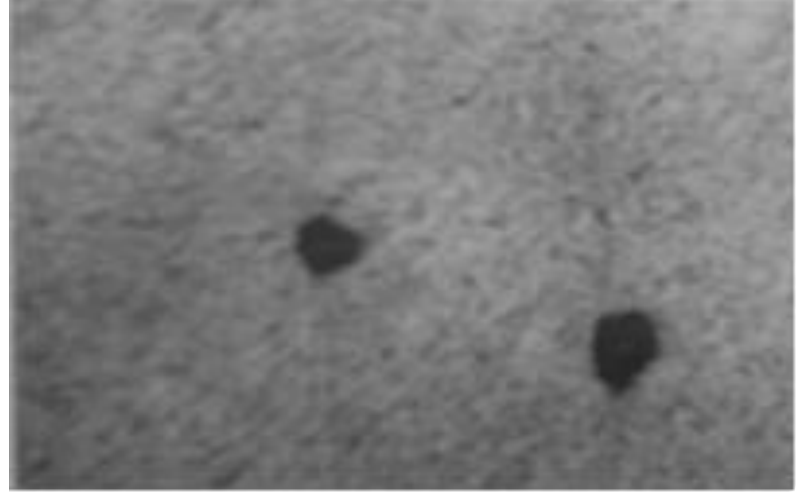

Fig. 12: Microstructure Image Porosity- Melt 1.

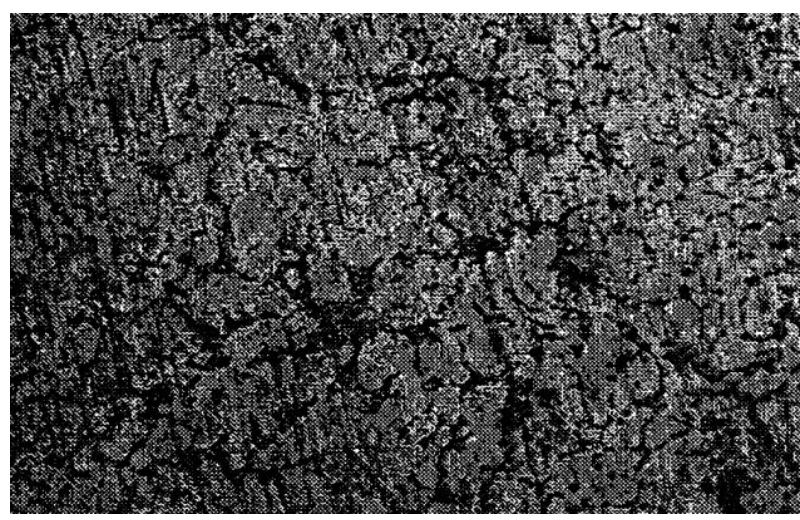

Fig. 13: Microstructure Image Shrinkage-Melt1.

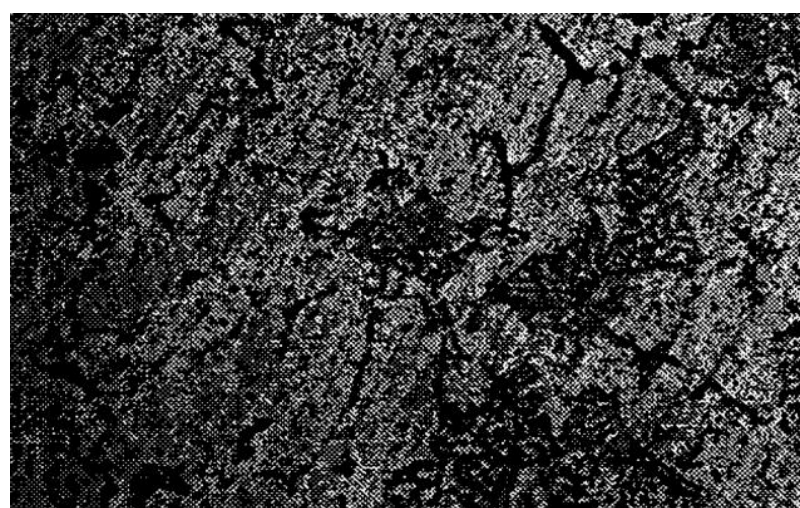

Fig. 14: Microstructure Image 200 Magnifications- Melt 1.

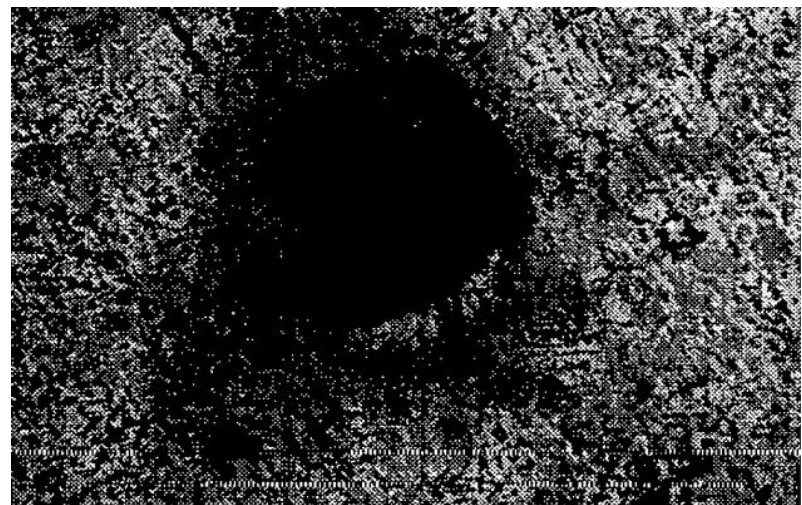

Fig. 15: Microstructure Image 500 Magnification. 


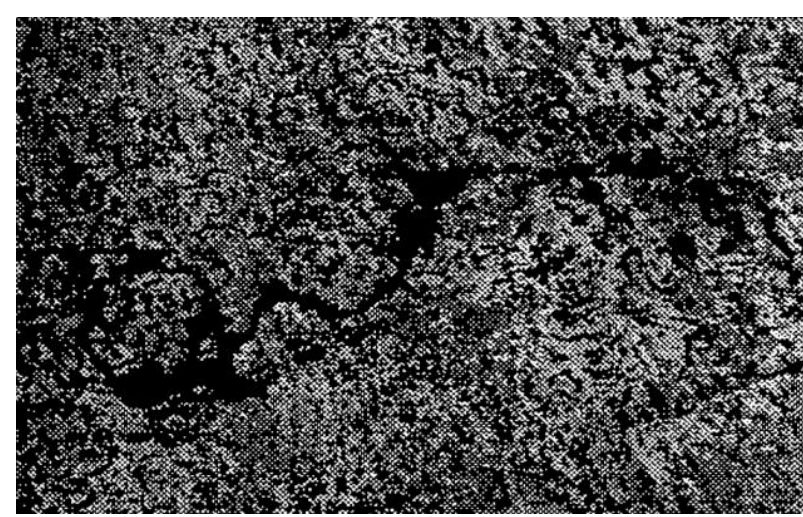

Fig. 16: Microstructure Image for Porosity- Melt 2.

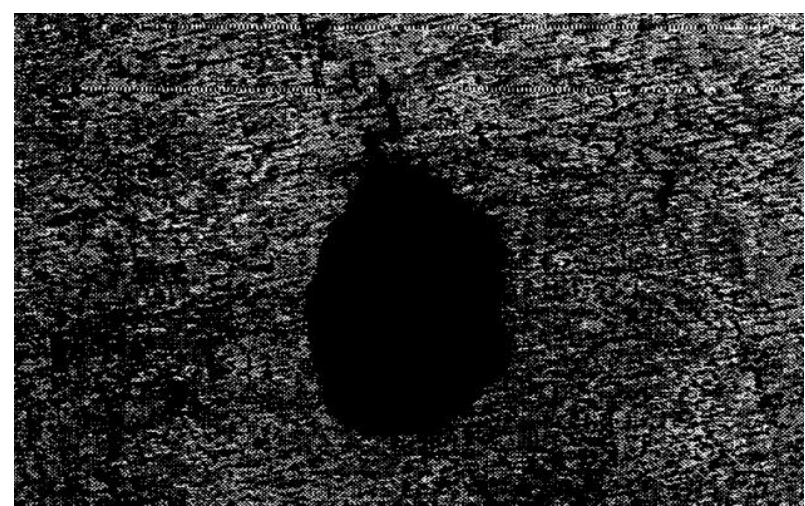

Fig. 17: Microstructure Image for Crack \& Shrinka.

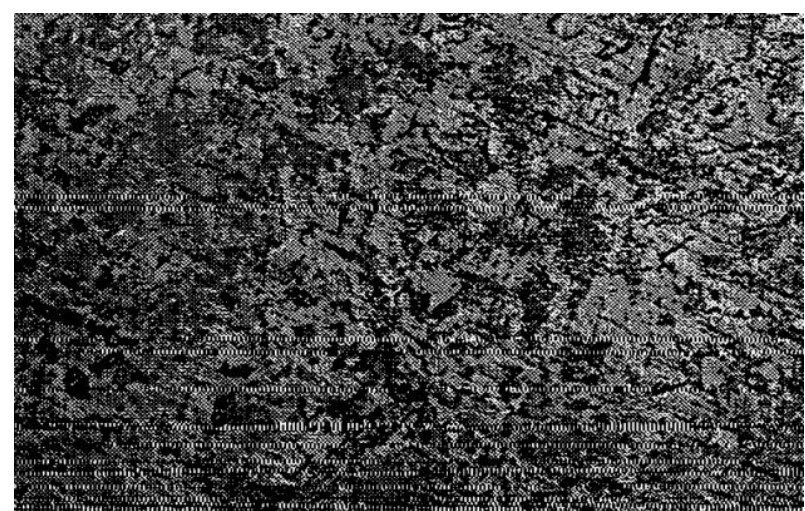

Fig. 18: Microstructure Image for Voids- Melt.

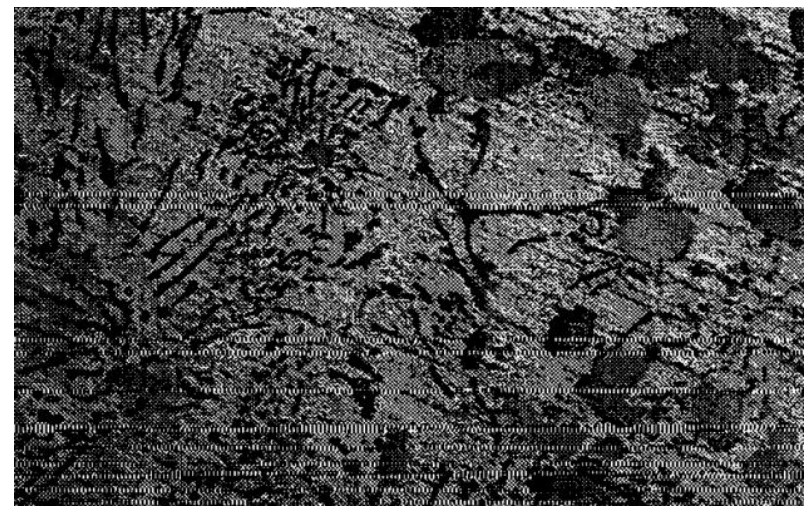

Fig. 19: Microstructure Image 200 Magnification- Melt 2.

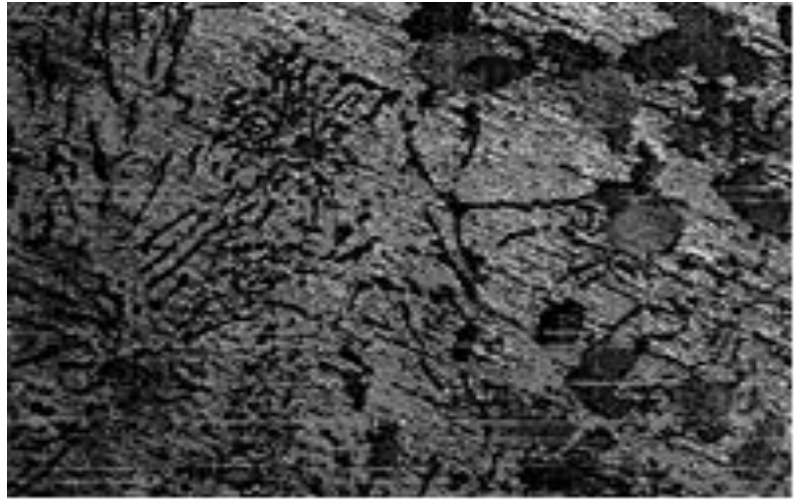

Fig. 20: Microstructure Image 500 Magnification- Melt 2.

\subsection{Brinell hardness testing}

Hardness is a measure of how resistant solid matter is to various kinds of permanent shape change when a force is applied. Hardness is dependent on ductility, elastic stiffness, plasticity, strain, strength and toughness.

Brinell hardness test is an indentation hardness test that can provide useful information about metallic materials. This kind of test chosen to check and compare the hardness difference between the two melts. This testing is done to show the hardness effect on the composite material due to addition of reinforcement material in $5 \%$ and $10 \%$ weights. The specimen to be prepared for the testing is $2.5 \mathrm{~mm}$ in diameter and weighs $62.5 \mathrm{kgf}$. one specimen from each specimen is prepared for hardness testing.

\begin{tabular}{llll}
\multicolumn{4}{c}{ Table 4: Brinell hardness Testing } \\
\hline S.no & Composition & Testing & Calculated value \\
\hline Melt 1 & Al6061+5\%N.C.G & Hardness & 84 \\
Melt 2 & Al6061+10\%N.C.G & Hardness & 83 \\
\hline
\end{tabular}

The hardness testing determines the measure of how resistant the solid matter is to various kinds of permanent shape change when a force is applied. The testing compares the rate of resistivity of each material and the effect of hardness due to addition of reinforcement material. The hardness testing shows that the addition of reinforcement material decreases the hardness of the material. For 5\% reinforcement the value is 84 and for $10 \%$ the value is reduced to 83 .

\subsection{Tensile testing}

Tensile testing, also known as tension testing is a fundamental materials science test in which a sample is subjected to a controlled tension until failure. The results from the test are commonly used to select a material for an application, for quality control, and to predict how a material will react under other types of forces A tensile specimen is a standardized sample cross-section. It has two shoulders and a gauge (section) in between. The shoulders are large so they can be readily gripped, whereas the gauge section has a smaller cross-section so that the deformation and failure can occur in this area. 


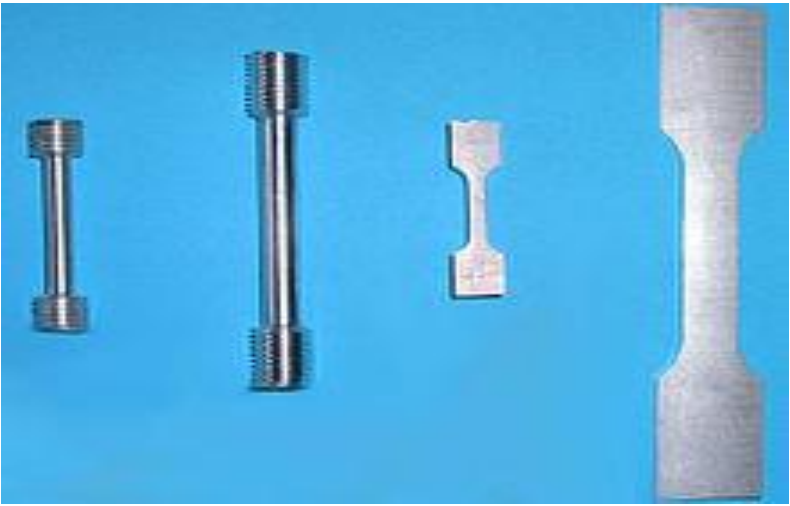

Fig. 21: Tensile Specimen.

Table 5: Tensile Testing

\begin{tabular}{llll}
\hline S.no & Composition & Testing & Calculated value \\
\hline 1 & Al6061 & Tensile & $148 \mathrm{~N} / \mathrm{mm}^{2}$ \\
2 & Al6061+5\%N.C.G & Tensile & $168 \mathrm{~N} / \mathrm{mm}^{2}$ \\
3 & Al6061+10\%N.C.G & Tensile & $169 \mathrm{~N} / \mathrm{mm}^{2}$ \\
\hline
\end{tabular}

The measurements taken are load and extension and a tensometer gives directly the load extension curve, and not the stress-strain curve. However, the stress-strain curve can be calculated from the cross-sectional area and the original length of the specimen. Such a curve can be labeled with specific identifiable point such as elastic limit, yield point and fracture.

\subsection{Wear testing}

Wear can also be defined as a process where interaction between two surfaces or bounding faces of solids within the working environment results in dimensional loss of one solid, with or without any actual decoupling and loss of material. Aspects of the working environment which affect wear include loads and features such as unidirectional sliding, reciprocating, rolling, and impact loads, speed, temperature etc.

Tests are used for quality control functions such as thickness, porosity, adhesion, strength, hardness, ductility, chemical composition, stress and wear resistance. Non-destructive tests include visual, penetrant dies, magnetic particle and acoustic techniques. Machining tests subject cutting tools to many wear parameters, including impact and shock, abrasion, adhesion and hot corrosion The limitations of these tests depend on the machine power available and the quality of the machine tool. Other coated components that are not used as cutting tools are assessed by laboratory wear tests and compared to field studies.

The test procedure for pin on disc apparatus is as follows:

Pin surface was made flat such that it will support load over its entire cross-section. This was achieved by running the test for about 30 min with relative loads varying from $0.5 \mathrm{~kg}, 1 \mathrm{~kg}, 1.5 \mathrm{~kg}$, $2 \mathrm{~kg}$ and at speeds 750 and 1000rpm. The load cell is connected to the disc table of the pin-on-disc machine so that to calculate the tangential forces acting on the discs. This tangential component helps in calculating the friction component. There was an electrical unit showing the load acting tangentially and the depth of wear, which increases with the application of load. Weight losses of the pin and disc were measured using a high precision electronic balance (with an accuracy of $0.001 \mathrm{gm}$.).

During the test, data (values of traction/friction Force and pin height) was acquired by a personal computer. Friction coefficient was calculated as ratio of traction force to applied normal load averaged over the duration of the wear test, while the wear rate is calculated as volume loss per unit applied pressure per unit Sliding distance. Each test was run for a fixed duration of $30 \mathrm{~min}$. Wear test under a particular load and speed conditions has been repeated and average values for friction and wear rates were calculated.

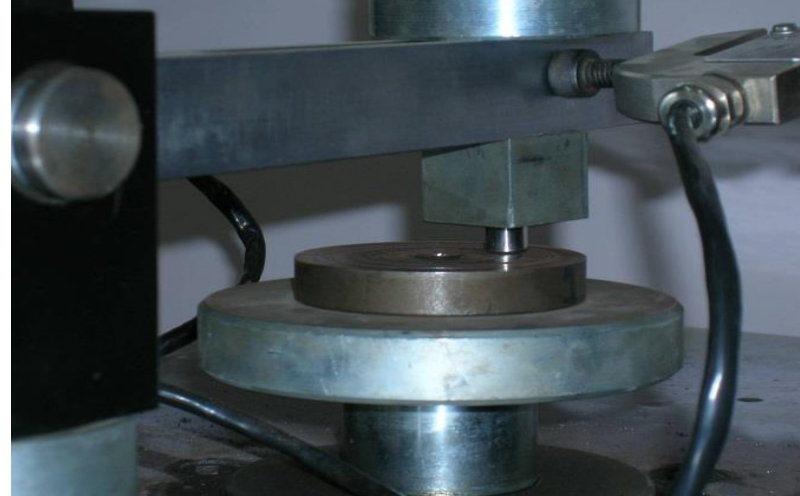

Fig. 22: Pin on Disc Type Wear Testing Machine.

The mass loss in each test was found and was used to find the wear rate of the pin material. The mass loss found was then divided with the density of the material to obtain the amount of volume loss taken place. The sliding distance is another aspect to be focused upon which is a function of speed of rotation and time of exposure.

Formulae Used:

Volume loss $(\mathrm{mm} 3)=$ Mass loss / density

Wear rate $(\mathrm{mm} 3 / \mathrm{m})=$ Volume loss $/$ sliding distance

Wear coefficient $(\mathrm{mm} 3 / \mathrm{Nm})=$ Volume loss $/($ Sliding distance $*$ Load)

Sliding distance $=(3.14 * \mathrm{D} * \mathrm{~N} * \mathrm{~T}) / 60$

Where:-

$\mathrm{D}($ diameter of disc $)=35 \mathrm{~mm}$

$\mathrm{N}$ (speed of rotation of disc) $=500 \mathrm{rpm}$

$\mathrm{T}($ time of rotation $)=31.82-32$ minutes

Radius of rotating circular path $=12 \mathrm{~mm}$

\subsection{Graphical results for wear testing}

\subsubsection{Load vs wear coefficient}

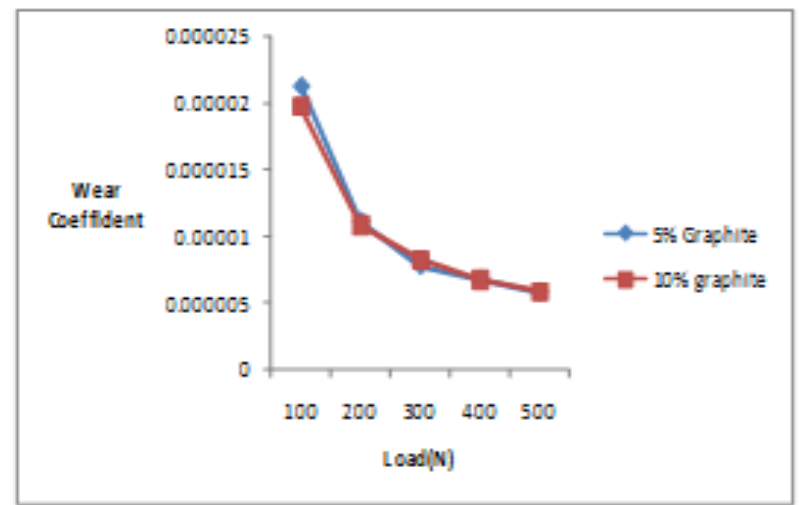

Fig. 23: Comparison of Melts 1, 2 


\subsubsection{Load vs wear rate}

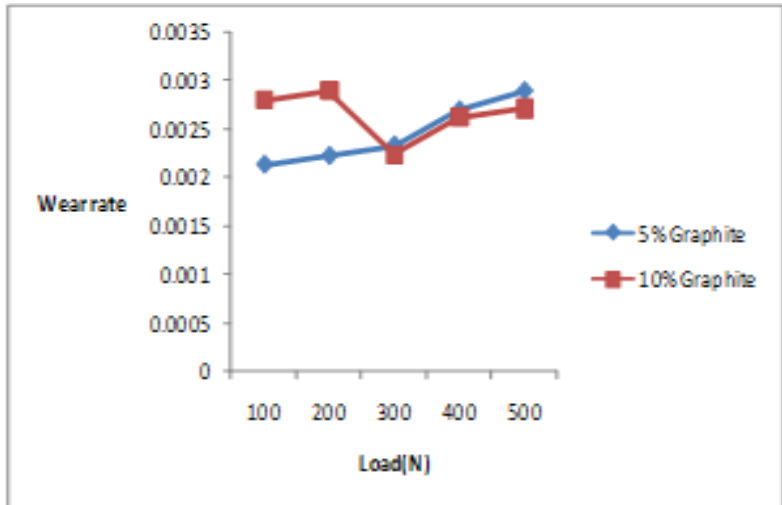

Fig. 24: Comparison of Melts 1, 2 .

\subsubsection{Load vs volume loss}

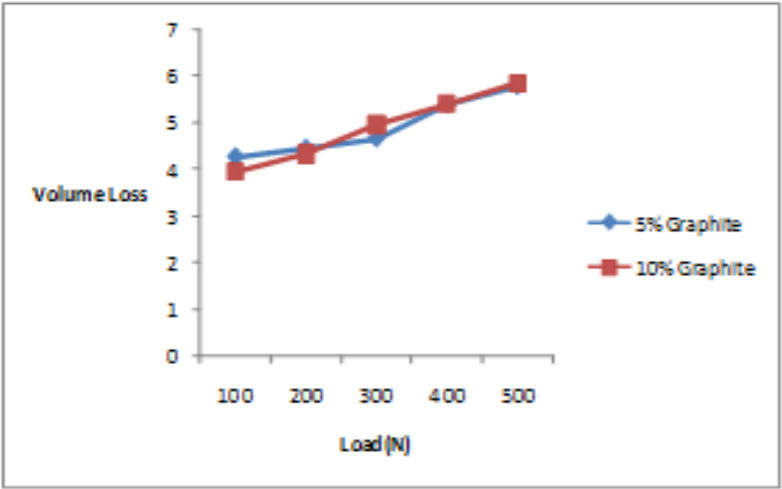

Fig. 25: Comparison of Melts 1, 2.

\subsubsection{Load vs mass loss}

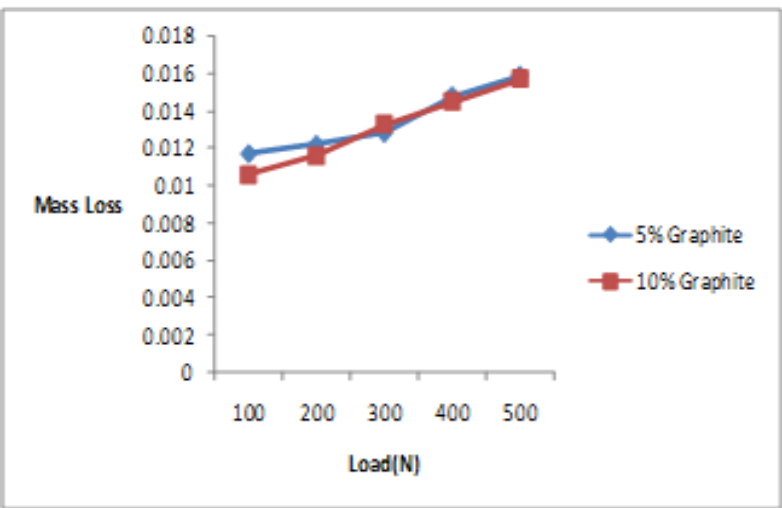

Fig. 26: Comparison of Melts 1, 2

\subsubsection{Sliding distance vs wear coefficient}

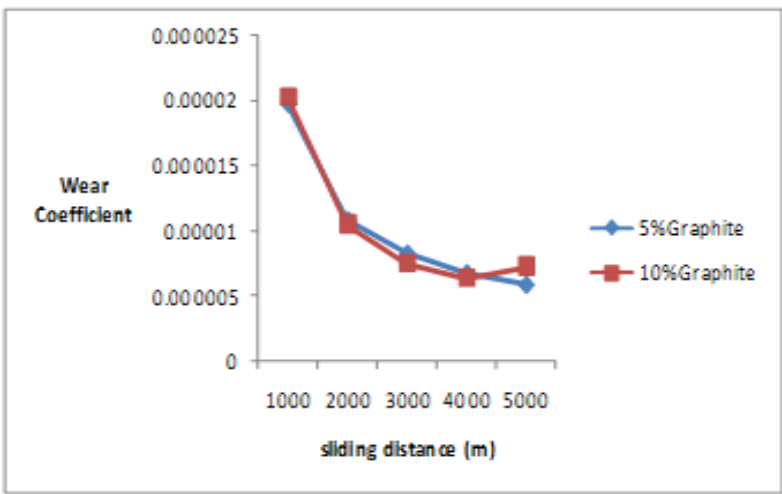

Fig. 27: Comparison of Melts 1, 2 .

\subsubsection{Sliding distance vs wear rate}

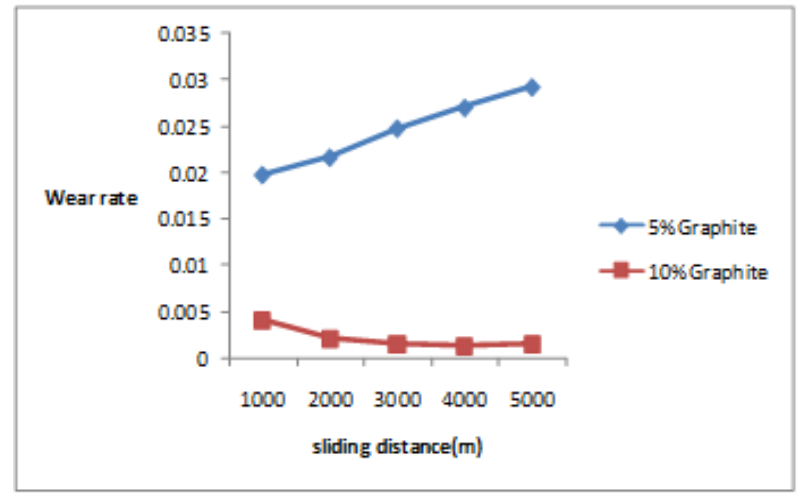

Fig. 28: Comparison of Melts 1, 2 .

\subsubsection{Sliding distance vs volume loss}

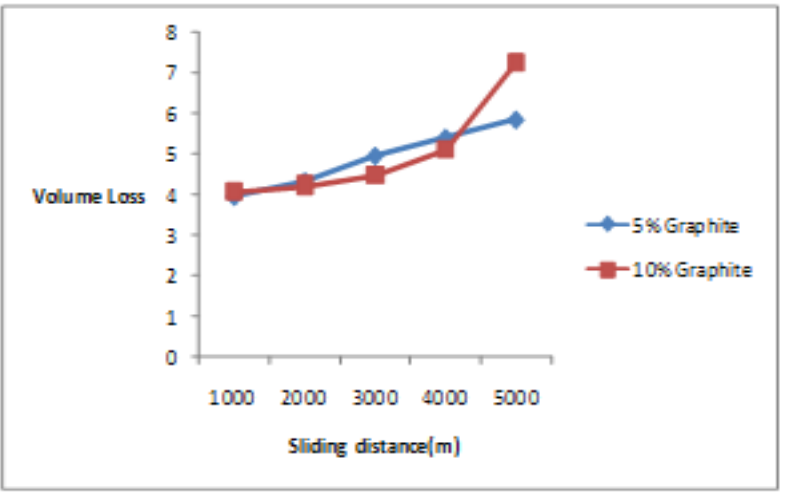

Fig. 29: Comparison of Melts 1, 2.

\subsubsection{Sliding distance vs mass loss}

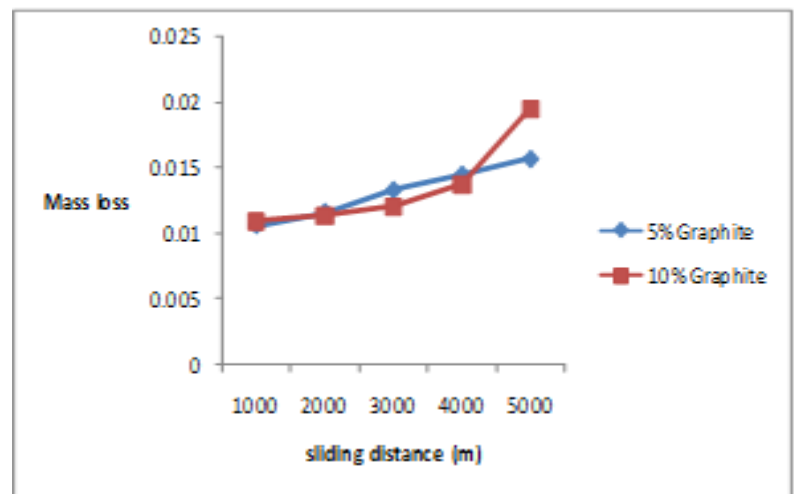

Fig. 30: Comparison of Melts 1, 2 .

\section{Conclusion}

The microstructure testing performed on optical microscope indicates that the cracks and voids were more large and prominent in the melt 2 containing 10\% reinforcements and the same cracks were less visible in the melt 1 containing $5 \%$ of reinforcements. Porosity and holes were observed to be more in melt 2 and less in melt

The hardness test indicates that the addition of reinforcements to the base material improves the resistance and increases its withstanding capacity to strain. The results show that melt 1 has more hardness withstanding properties than the melt 2 and has much resistance to strain.

In wear tests are carried out with a high degree of simulation of the service situation, then the results can be used with considerable confidence in selecting the best wear-resistant coating system. Thin coatings require greater care in wear tests in order to avoid penetration, which requires lighter loads and shorter test durations. 
Surface roughness also influences the tribological performance of a mechanical system. A small increase in the wear resistance of the melt with more reinforcement was observed. Hence the melt having more percentage of reinforcement was observed to be having more resistance to wear.

The tensile test carried indicates that A16061 resists the load applied on it and as the nickel-graphite reinforcement is increased in percentage, the ductility also increases which contributes in higher plastic region and increases the ultimate and yield strengths. Before adding NCG Al6061 has a certain value. After addition of NCG the value is found to be more.

\section{References}

[1] S.BISWAS and P.K.ROHATGI. "Tribological properties of cast gra phitic aluminum composites", Tribal, Int., 1983, 16(2), pp 89-102.

[2] T.W.CLYNE and P.J.WITHERS. "An introduction to metal matrix Composites", 1st ed., Cambridge University Press, Cambridge, 1993, pp 1-10

[3] K.K.CHAWLA. "Composite Materials", 2nd ed., Springer, New York, 1998, pp 3-5.

[4] I.A. IBRAHIM, "Particulate Reinforced Metal Matrix Composites A Review", J. Mater.Sciene., 1991, 26(5), pp.1137-1156

[5] KARNEZIS P.A. "Microstructure and tensile properties of squeeze cast Sic particulate reinforced Al-7si alloy", materials science and technology gy, 1998, vol. 17, pp 97-107

[6] M.L.TED GUO, CHI. - Y.A. TSAO. "Tribological behavior of aluminum/sic/nickel-coated graphite hybrid composites", Material Science and Engineering A333 (2002) pp 134-145.

[7] S.A.PELASEYYED. "Characterization of aluminium/graphite particulate composites synthesized using novel method termed - in situ powder metallurgy", Mater. Sci.Eng. A, 2004, 385, pp 258-266.

[8] S. RAY, "Review Synthesis of Cast Metal Matrix Particulate Composites”, J. Mater. Sci., 1993, 28(20), pp5397-5413

[9] P.K.ROHATGI, B.C.PAI. "Effect of microstructure and mechanica properties on the seizure resistance of cast aluminum alloys", Wear 28 (1974) pp 353-367.

[10] SARAVANABHAVAN. "Synthesis, Characterization and Mechanical Behavior of Nickel Coated Graphite on Aluminum Matrix Composite",

International Journal of Research in Engineering and Technology, 2013 vol 02, pp. $749-755$

[11] YOUNG- HO SEO, CHUNG GIL KANG. “ The effect of applied pressure on particle dispersion characteristics and mechanical properties in melt stirring squeeze cast Sicp / Al composite, Journal of materials processing technique",1995 vol 55,pp. $370-379$. 